\title{
Pengaruh Citra Destinasi, Aksessibilitas Wisata Terhadap Minat Kunjung Ulang Wisatawan Ke Wisata Bahari Desa Benan
}

\author{
Iranita, Putra Alamsyah
}

Fakultas Ekonomi Universitas Maritim Raja Ali Haji, Tanjungpinang, Kepulauan Riau, Indonesia

\begin{abstract}
ABSTRAK : Penelitian ini bertujuan untuk mengetahui pengaruh citra destinasi, aksessibilitas, dan motivasi wisata terhadap minat kunung ulang wisatawan wisata bahari Desa Benan. Pengaruh citra destinasi dan aksessibilitas wisata secara parsial terhadap minat kunjung ulang, pengaruh citra destinasi dan aksessibilitas wisata secara simultan terhadap minat kunjung ulang. Populasi pada penelitian ini seluruh wisatawan wisata bahari Desa Benan, penentuan sampel menggunakan metode insidental sampling dengan teori Resco hingga didapat 30 responden. Data yang digunaka dalam penelitaian ini adalah data primer yangb diperoleh dari angket/kuesioner. Metode analisis yang digunakan dalam penelitian ini adalah uji deskriptif, uji kualitas data, uji asumsi klasik, analisis regresi linier berganda, dan uji hipotesis. Hasil analisis pada penelitian ini menunjukan bahwa variabel citra destinasi seraca parsial berpengaruh signifikan terhadap variabel minat kunjung ulang, variabel aksessibilitas secara parsial berpengaruh signifikan terhadap varibel minat kunjung ulang. Hasil analisis pada penelitian ini menunjukan bahwa secara simultan varibel citra destinasi dan aksessibilitas wisata berpengaruh signifikan terhadap variabel minat kunjung ulang. Variabel citra destinasi dan aksessibilitas wisata dalam penelitian ini berkontribusi sebesar $42,5 \%$ terhadap minat kunjung ulang wisatawan wisata bahari Desa Benan.
\end{abstract}

Kata Kunci: Citra Destinasi, Aksessibilitas, Minat Kunjung Ulang

\begin{abstract}
This study aims to determine the effect of destination image, accessibility, and tourist motivation on the revisit of marine tourism tourists in Benan Village. The influence of destination image and tourism accessibility partially on the interest of the repeat visit, the influence of the destination image and tourist accessibility simultaneously on the interest of the repeat visit. The population in this study were all marine tourism tourists in Benan Village, determining the sample using the incidental sampling method with Resco theory until 30 respondents were obtained. The data used in this study are primary data obtained from questionnaires / questionnaires. The analytical method used in this research is descriptive test, data quality test, classic assumption test, multiple linear regression analysis, and hypothesis testing. The results of the analysis in this study show that the partial image destination destination variable has a significant effect on the revisiting interest variable, the accessibility variable partially has a significant effect on the revisiting interest variable. The results of the analysis in this study indicate that the simultaneous variable of the destination image and tourism accessibility significantly influence the variable of interest in the return visit. Destination image and tourism accessibility variables in this study contributed $42.5 \%$ to the interest of re-visiting marine tourism tourists in Benan Village.
\end{abstract}

Keywords: Destination Image, Accessibility, Revisiting Interest

Email Address : iranita@umrah.ac.id 


\section{PENDAHULUAN}

\section{Latarbelakang}

Pariwisata salah satu sumber devisa negara selain dari sektor migas yang sangat potensial dan mempunyai pengaruh besar dalam membangun perekonomian yang saat ini pertumbuhannya sangat pesat. Pengembangansektorpariwisatayangdilakukand enganbaikakanmampu menarik wisatawan domestik maupun wisatawan asing untuk datang dan membelanjakan uangnya dalam kegiatan berwisatanya.

Citra destinasi yang dimiliki wisata Bahari Desa Benan dalam pandangan beberapa orang dan peneliti merupakan citra destinasi yang mewarkan pemandangan dan perasaan yang eksotik, karena memiliki destinasi yang terkesan sangat natural mulai dari pemandangan yang indah, iklim yang hangat sampai ke masyarakatnya yang memiliki budaya yang ramah terhadap wisatawan ataupun pengujung yang datang dan berkujung ke wisata Bahari Desa Benan, khususnya pada penawaran destinasi wisata di bidang bahari yang menjadi keunggulan di wisata Bahari Desa Benan tersebut artinya semakin bagus suatu citra destinasi maka akan semakin inginseseorang melakukan kunjungan kembali, Menurut Hayati, dkk (2016) citra memiliki pengaruh terhadap revisit intention (minat berkunjungkembali).

Aksesbilitas juga merupakan yang hal yang memiliki peranan yang penting terhadap minat berkunjung kembali. Zaman sudah semakin canggih dunia teknologi semakin pesat begitu juga dengan aksesbilitas akan semakin memberikan penawaran yang semaksimal mungkin untuk memberikan kenyamanan kepada konsumenya dengan harapan agar selalu menjadi pilihan konsumen.

Wisata Bahari Desa Benan menawarkan akses tranportasi laut yang akan membawa para pengunjung untuk mencapai pulau Benan tersebut dengan mengunakan Kapal Feri yang berkapasitas lebih kurang 200 orang penumpang yang hanya melakukan operasional perjalan satu hari hanya sekali, dengan jalur akses yaitu kota Tanjungpinag, kota Batam, Daik Lingga, Dabok, Senanyang, dan pulau-pulau lain disekitarnya. jadi wisatwan atau pengunjung tidak bisa untuk melakukan perjalan pulang pergi dalam sehari kecuali menggunkan tranfortasi pribadi atau menyewa jasa tranfortasi, namun untuk jarak yang di tempuh lumayan memakan waktu kebanyakan pengunjung akan menginap semalam dari pada mealakukan perjalan pulang pergi. Artinya semakin bagus fasilitas aksessibilitas disediakan maka akan semakin ingin seseorang melakukan kunjungan kembali.

Minat kunjung ulang wisatawan biasanya muncul karena adanya persepsi positif atau pengalaman terhadap daya tarik wisata. Dalam hal ini teori minat kunjung ulang diambil dari teori minat beli ulang terhadap suatu produk, sehingga dalam beberapa kategori minat berkunjung dapat diaplikasikan terhadap minat beli.

Minat adalah dorongan untuk memotivasi seseorang melakukan tindakan yang tanpa disadar atau tidak akan dilakukan, Aviolitasona (2017). Hidayat dan Sutomo, (2017), menyatakan niat berkunjung kembali adalah niat dan keinginan berkunjung lebih sering. Dalam kaitannya dengan minat berkunjung ulang, minat merupakan pelanggan potensial yang mempunyai arti pelanggan yang pernah datang kembali dan menggunakan jasakembali.

Tabel 1.

Data Kunjungan Wisata Bahari Desa Benan

\begin{tabular}{|c|c|}
\hline 4 Bulan Terakhir & Total Pengunjung \\
\hline Oktober & $\mathbf{1 4 0}$ \\
\hline November & $\mathbf{1 4 6}$ \\
\hline Desember & $\mathbf{1 6 5}$ \\
\hline Januari & $\mathbf{1 5 9}$ \\
\hline
\end{tabular}

Sumber : Pengelola Wisata Bahari Desa Bahari Desa Benan

Berdasarkan data diatas, dapat dilihat terjadi tidak stabilnya dan tidak ada peningkatan yang pesat terhadap jumlah wisatawan yang berkunjung ke wisata Bahari Desa Benan mengingat dan menimbanng bahwa wisata Bahari Desa Benan termasuk sudah lama didirikan oleh pemerintah setempat terhitung mulai dari tahun 2009.

Menurut pengelola wisata Bahari Desa Benan ini terjadi karenaWisata Bahari Desa Benan merupakan destinasi wisata yang terletak jauh dari pusat keramaiaan atau kota. Dan juga 
merupakan wisata yang belum terlalu dikenal oleh orang ramai padahal jika dilihat dengan seksama wisata Bahari Desa Benan memiliki destinasi yang sangat bagus dan kesanya sangat natural khususnya dibagian pantai dan lautnya.

Kemudian menurut pengakuan pengelola kebanyakan wisatawan yang berkunjung itu diwaktu libur nasional seperti hari sabtu dan minggu, wisatawan mengisi waktu liburnya untuk mengurangi stres serta berkumpul bersama teman, sahabat, dan keluarga. Terkadang juga wisatawan melakukan kunjungan untuk melakukan bisnis.

Berdasarkan penjelasan fenomenafenomena diatas, maka judul penelitian ini adalah " Pengaruh Citra Destinasi dan Aksesibilitas Wisata Terhadap Minat Kunjung Ulang Wisatawan Ke Wisata Bahari Desa Benan.”

\section{Tujuan Penelitian}

Tujuan penelitian merupakan jawaban atau ssasaran yang ingin dicapai penulis dalam sebuah penelitian, oleh sebab iru, tujuan penelitian ini adalah:

1) Untuk mengetahui pengaruh citra destinasi terhadap minat kunjungulang

2) Untuk mengetahui pengaruh aksessibilitas terhadap minat kunjungulang

3) Untuk mengetahui citra destinasi dan aksessibilittas wisata terhadap minat kunjungulang

\section{Citra Destinasi}

Jorgensen (dalam Aviolitasona, 2017: 9), menyebutkan bahwa citra destinasi didefinisikan tidak hanya sebagai atribut destinasi tetapi juga kesan menyeluruh yang ditampilkan oleh destinasi.

\section{Aksesssibilitas}

Menurut Black, (dalam Yuristasari, dkk, 2016 :318), aksesibilitas adalah suatu ukuran kenyamanan atau kemudahan lokasi tata guna lahan berinteraksi satu sama lain, dan mudah atau sulitnya lokasi tersebut dicapai melalui transportasi.

Salah satu variabel yang dapat dinyatakan apakah tingkah aksesibilitas itu tinggi atau rendah dapat dilihat dari banyaknya sistem jaringan yang tersedia pada daerah tersebut

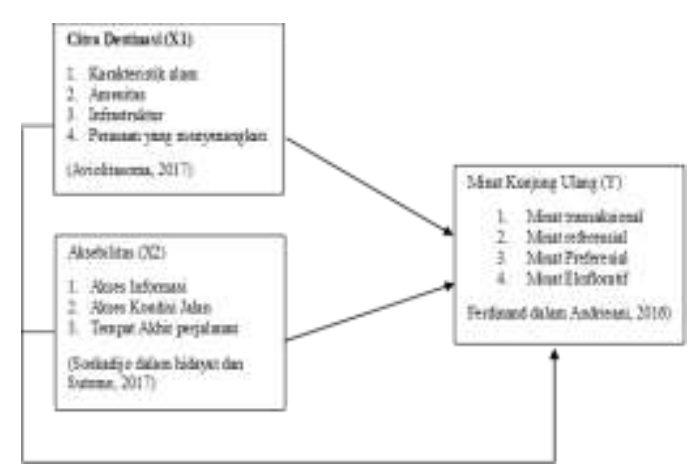

Gambar 1

Kerangka Pemikiran

\section{Minat Kunjung Ulang}

Setyo, (dalam Aviolitasona, 2017: 12). Baker dan Crompton, (dalam Hidayat dan Sutomo, 2017: 203), menyatakan niat berkunjung kembali adalah niat dan keinginan berkunjung lebih sering.

\section{Hipotesis}

Hipotesis penelitian ini adalah sebagai berikut:

$\mathrm{H}_{1}$ : Diduga citra desdinasi secara parsial berpengaruh signifikan terhadap minat kunjung ulang

$\mathrm{H}_{2}$ :Diduga aksessibilitas secara parsial berpengaruh signifikan terhadap minat kujung ulang

$\mathrm{H}_{3}$ : Diduga citra destinasi dan aksessibilitas wisata secara simultan berpebgaruh signifikan terhadap minat kunjung ulang.

\section{METODE PENELITIAN}

Metode penelitian pada dasarnya merupakan cara ilmiah untuk mendapatkan datadengan tujuan dan kegunaan tertentu, (Sugiyono, 2016: 2), dengan prosedur dan teknik pengumpulan data sesuai dengan pendekatan secara kuantitatif dan kualitatif. Jenis penelitian yang di lakukan dalam penenlitian in adalah penelitian kuantitatif dengan menggunakan analisis statistic dan analisis regresi. 


\section{Populasi}

Adapun yang menjadi populasi dalam penelitian ini adalah seluruh wisatawan wisata Bahari Desa Benan yang telah melakukan kunjungan minimal 1 kali kunjungan

\section{Sampel Penelitian}

Menurut Sugiyono (2017:81), Sampel merupakan bagian dari jumlah dan karakteristik yang dimiliki oleh populasi tersebut dalam penelitian ini untuk memperoleh sampel yang mewaakili populasi secara keseluruhan yaitu menggunakan teknik Sampling Insidental, yaitu teknik penentuan sampel berdasarkan kebetulan/insidetal bertemu dengan peneliti dapat di gunakan sebagai sampel, bila di pandang orang yang kebetulan di temui itu cocok sebagai sumber data (Sugiyono: 85).

Untuk memperkecil sampel maka peneliti mengunkan teori Resco dalam Sujarweni (2015: 81), yang memberikan pedoman bahwa penentuan sampel di antara $30 \mathrm{~s} / \mathrm{d} 500$ elemen. Jadi disini peneliti mengambil sampel yang bisa mewakili populasi dalam penelitian ini yaitu 30 orang wisatawan wisata Bahari Desa Benan.

Menurut Ghozali (2016:94), dalam analisis regresi, selain mengukur kekuatan hubungan antara dua variabel atau lebih, juga menunjukan arah hubungan antara variabel dependen dan variabel independen. Pada penelitian ini regresi yang di gunakan adalah regresi linier berganda. Adapun model yang akan di gunakan dalam penelitian ini sebagai berikut :

\section{$\mathrm{Y}=\mathrm{a}+\mathrm{b} 1 \mathrm{X} 1+\mathrm{b} 2 \mathrm{X} 2+\mathrm{e}$}

\section{Keterangan:}

Y :Minat Berkunjung Ulang

a : Intercept (Konstanta)

b1 : Koefisien regresi untuk X1

b2 : Koefisien regresi untuk X2

$\mathrm{X} 1$ : Variabel bebas pertama

$\mathrm{X} 2$ : Variabel bebas kedua

e : Nilai error

\section{HASIL DAN PEMBAHASAN}

\section{Statistik Deskriptif}

Statistik deskriptif bertjuan untuk melihat gambaran umum data yang digunakan dalam penelitian ini. Berikut hasil perhitungan statistik deskriptif dengan SPSS 24 pada tabel 2.

Berdasarkan hasil uji statistik deskriptif pada tabel di atas maka dapat dilihat hasil nilai minimum, maksimum, mean dan standar deviasi dari masing-masing variabel penelitian. Dimana variabel bebas pertama yaitu citra destinasi nilai terendahnya yaitu 42 , dan nilai tertinggi 53, dengan nilai rata-rata (mean) sebesar 48,40 serta nilai standar deviasi sebesar 3.147.

Tabel 2. Hasil Uji Statistik Deskriptif

\begin{tabular}{|c|c|c|c|c|c|}
\hline \multicolumn{6}{|c|}{ DescriptiveStatistics } \\
\hline & $\mathrm{N}$ & Min & $\begin{array}{c}\mathrm{Ma} \\
\mathrm{x}\end{array}$ & Mean & $\begin{array}{c}\text { Std. } \\
\text { Deviatio } \\
\mathrm{n}\end{array}$ \\
\hline Citra_Destiasi & 30 & 42 & 53 & 48,40 & 3,147 \\
\hline Aksessibilitas & 30 & 25 & 32 & 29,37 & 2,076 \\
\hline $\begin{array}{l}\text { Minat_Kunjung_Ul } \\
\text { ang }\end{array}$ & 30 & 15 & 19 & 17,40 & 1,133 \\
\hline Valid N (listwise) & 30 & & & & \\
\hline
\end{tabular}

Selanjutnya variabel bebas kedua yaitu aksessibilitas dimana nilai terendahnya yaitu 25 dan nilai tertinggi 32 , dengan nilai rata-rata (mean) sebesar 29.37 serta nilai standar deviasi 2.076. Variabel terikat yaitu minat kunjung ulang dengan nilaiterendahnya15dannilaitertinggi19, dengannil airata-rata(mean)sebesar17.40 serta nilai standar deviasi sebesar 1.133.

\section{Uji Validitas Dan Uji Reliabel}

Berdasarkan hasil uji validitas yang dilakukan dapat diperoleh hasil bahwa semua instrumen dalam penelitian ini di nyatakan Valid yaitu nilai $r$ hitung lebih besar dari pada nilai $r$ tabel sebesar 0,3610 sehingga semua instrumen dapat digunakan dalam penelitian ini. Dari hasil uji reliabilitas dengan menggunakan. variabel keterampilan kerja, fasilitas kerja, semangat kerja dan produktivitas kerja mempunyai nilai Cronbach Alpha lebih besar dari Cronbach Alpha yang disarankan yaitu > 0,70 Sehingga intrumen layak untuk digunakan 
dalam penelitian.

\section{Uji Asumsi Klasik \\ Uji Normalitas}
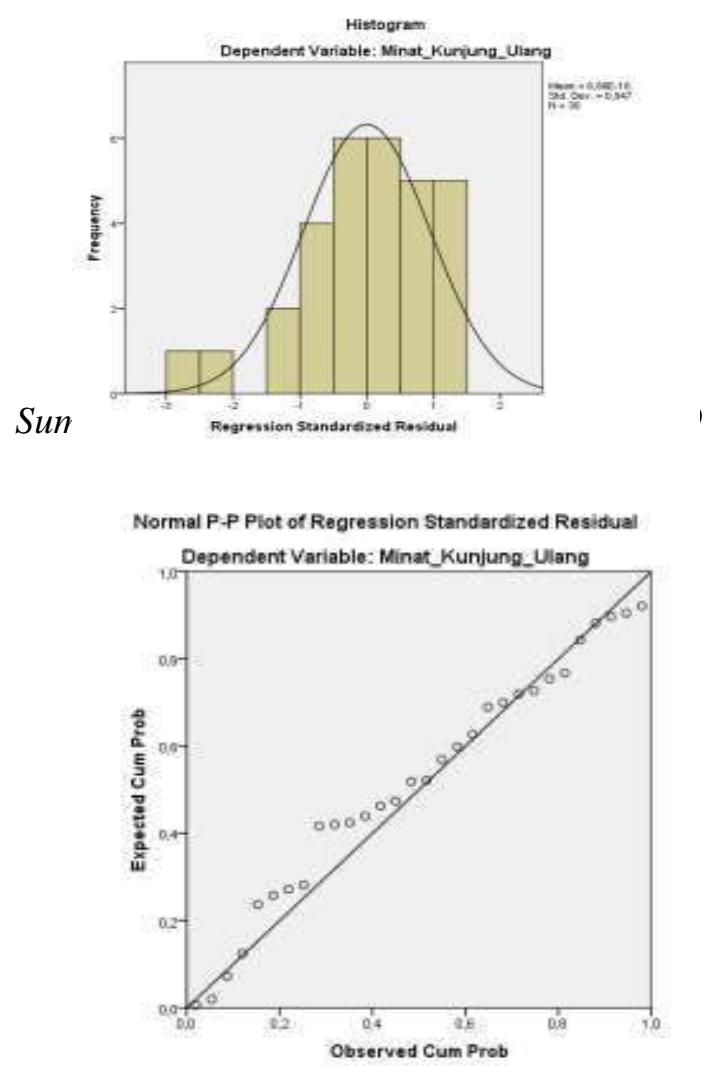

Sumber: data primer (kuesiner), diolah 2019

Gambar 2\&3

\section{Hasil Grafik Histogram \& Grafik P-}

Plot

Berdasarkan gambar 2 dan 3 di atas, pada grafik histogram terlihat bahwa pola berdistribusi normal. Namun kesimpulan dengan grafik histogram ini belum dapat dipastikan kenormalan datanya untuk jumlah yang kecil. Begitu juga dengan grafik P-P Plot, sekilas memang terlihat normal karena distribusi data residualnya terlihat mendekati normal. untuk mendapatkan hasil yang lebih pasti dan meyakinkan dilakukan uji statistik non parametik dengan uji Kolmogorov- Smirnov (K-S) dengan nilai signifikan di atas 0,05 (> $0,05)$, maka data berdistribusi normal.

Berdasarkan Uji Kolmogorov-Smirnov pada tabel 4.14 di atas, dapat dilihat bahwa nilai Asymp. Sig. (2-tailed) sebesar 0,200 di atas 0,05 $(>0,05)$. Hal ini berarti data residual terdistribusi secaranormal.

\section{Uji Multikolonieritas}

\section{Tabel 3}

\section{Hasil Uji Multikolonieritas}

\begin{tabular}{|r|l|r|r|}
\hline \multirow{2}{*}{\multicolumn{2}{|l|}{ Model }} & \multicolumn{2}{|c|}{ Collinearity Statistics } \\
\cline { 2 - 4 } & Tolerance & \multicolumn{1}{c|}{ VIF } \\
\hline 1 & (Constant) & & \\
\hline & Citra_Destiasi &, 999 & 1,001 \\
\hline & Aksessibilitas &, 999 & 1,001 \\
\hline
\end{tabular}

Sumber: data Primer (kuesuioner), diolah 2019

Berdasarkan tabel di atas, dapat dilihat hasil perhitungan menunjukkkan nilai tolerance variabel independen memiliki tolerance $>0,10$ dan hasil perhitungan nilai VIF menunjukkan nilai $<10$. Dengan demikian dapat disimpulkan bahwa tidak terjadi multikolonieritas antar variabel independen dalam modelregresi.

\section{Uji Heteroskedastisitas}

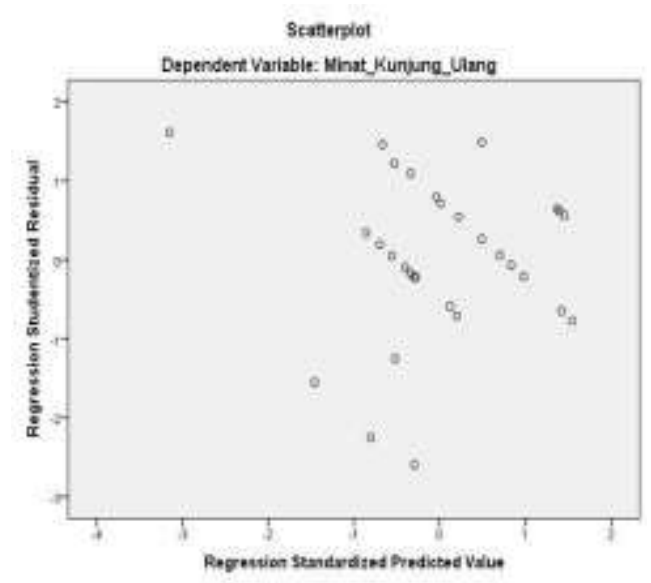

Sumber: data Primer (kuesuioner), diolah 2019

\section{Gambar 3 Grafik Scatterplot}

Dari hasil scatterplot di atas, terlihat bahwa titik-titik menyebar secara acak serta tersebar baik di atas maupun di bawah 0 pada sumbu $\mathrm{Y}$ dan tidak membentuksuatu pola tertentu. Dengan 
demikian dapat disimpulkan bahwa tidak terjadi masalah heteroskedastisitas pada model regresi, sehingga model regresi layak dipakai untuk memprediksi produktivitas kerja berdasarkan variabel independen yaitu keterampilan kerja, fasilitas kerja dan semangatkerja.

\section{Analisis Regresi Linier Berganda}

Tabel 4

Hasil Uji Regresi Liner berganda

\begin{tabular}{|c|c|c|c|c|c|c|}
\hline \multirow{2}{*}{\multicolumn{2}{|c|}{ Model }} & \multicolumn{2}{|c|}{$\begin{array}{l}\text { Unstandardized } \\
\text { Coefficients }\end{array}$} & \multirow{2}{*}{$\begin{array}{c}\begin{array}{c}\text { Standardized } \\
\text { Coefficients }\end{array} \\
\text { Beta }\end{array}$} & \multirow[b]{2}{*}{$\mathrm{t}$} & \multirow[b]{2}{*}{ Sig. } \\
\hline & & B & $\begin{array}{l}\text { Std. } \\
\text { Error }\end{array}$ & & & \\
\hline 1 & (Constant) & $-3,224$ & 4,179 & &,- 772 & ,447 \\
\hline & Citra_Destiasi &, 141 &, 051 & ,392 & 2,765 &, 010 \\
\hline & Aksessibilitas & ,236 &, 078 & ,433 & 3,044 & 005 \\
\hline
\end{tabular}

Berdasarkan tabel di atas dapat di susun persamaan regresi linier berganda sebagai berikut: Minat Kunjung Ulang $(Y)=-3,224+0,141\left(X_{1}\right)+$ $0,236(\mathrm{X} 2)$

\section{Uji Hipotesis}

Uji t ( Pengujian Secara Parsial)

Tabel 5

Hasil Uji Secara Parsial

\begin{tabular}{|l|l|c|c|c|c|r|}
\hline \multirow{2}{*}{\multicolumn{2}{|c|}{}} & \multicolumn{2}{|c|}{$\begin{array}{c}\text { Unstandardized } \\
\text { Coefficients }\end{array}$} & $\begin{array}{l}\text { Standardized } \\
\text { Coefficients }\end{array}$ & & \\
\cline { 2 - 6 } & B & $\begin{array}{c}\text { Std. } \\
\text { Error }\end{array}$ & Beta & \multirow{2}{*}{ t } & \multirow{2}{*}{ Sig. } \\
\hline 1 & (Constant) & $-3,224$ & 4,179 & &,- 772 &, 447 \\
\hline & Citra_Destiasi &, 141 &, 051 &, 392 & 2,765 &, 010 \\
\hline & Aksessibilitas &, 236 &, 078 &, 433 & 3,044 &, 005 \\
\hline
\end{tabular}

Sumber: data Primer (kuesuioner), diolah 2019

Kesimpulan yang dapat diambil dari analisis tabel di atas adalah sebagai berikut:

\section{(a) Variabel Citra Destinasi}

Hipotesis 1:

Berdasarkan hasil pengujian yang telah dilakukan, diperoleh nilai $t_{\text {hitung }}$ untuk variabel citra destinasi 2,765 dengan hasil sig. 0,010<0,05 dan berdasarkan perbandingan $t_{\text {hitung }}$ dengan $t_{\text {tabel }}$ $\left(\mathrm{t}_{\text {tabel }} \alpha=0,05, \mathrm{df}=27\right)$ didapat $\mathrm{t}_{\text {hitung }} 2,765$ lebih besar dari $t_{\text {tabel }} 1,70329(2,765>1,70329)$ maka H0 ditolak dan H1 diterima, dapat disimpulkan bahwa citra destinasi (X1) berpengaruh signifikan terhadap minat kunjung ulang(Y).

\section{(b) Variabel Citra Aksessibilitas}

\section{Hipotesis 2:}

Berdasarkan hasil pengujian yang telah dilakukan, diperoleh nilai $t_{\text {hitung }}$ untuk variabel aksessibilitas 3,044 dengan hasil sig. 0,005 <0,05 dan berdasarkan perbandingan $\mathrm{t}_{\text {hitung }}$ dengan $\mathrm{t}_{\text {tabel }}\left(\mathrm{t}_{\text {tabel }} \alpha\right.$ $=0,05, \mathrm{df}=27)$ didapat $\mathrm{t}_{\text {hitung }} 3,044$ lebih besar dari $t_{\text {tabel }} 1,70329(3,044>1,70329)$ maka $\mathrm{H} 0$ ditolak dan $\mathrm{H} 2$ diterima, dapat disimpulkan bahwa aksessibilitas (X2) berpengaruh signifikan terhadap minat kunjung ulang $(\mathrm{Y})$.

\section{Uji F (Pegujian secara Simultan)}

\section{Tabel 6}

\section{Hasil Uji F secara Simultan}

\begin{tabular}{|l|l|l|r|r|r|r|}
\hline \multicolumn{7}{|c|}{ ANOVA $^{\text {a }}$} \\
\hline \multicolumn{2}{|c|}{$\begin{array}{l}\text { Sum of } \\
\text { Model }\end{array}$} & $\begin{array}{l}\text { Mean } \\
\text { Squar } \\
\text { Squares }\end{array}$ & df & e & Sig. \\
\hline \multirow{2}{*}{1} & $\begin{array}{l}\text { Regressio } \\
\mathrm{n}\end{array}$ & 18,018 & 3 & 6,006 & $\begin{array}{c}8,14 \\
1\end{array}$ &, $001^{\mathrm{b}}$ \\
\cline { 2 - 7 } & Residual & 19,182 & 26 &, 738 & & \\
\hline & Total & 37,200 & 29 & & & \\
\hline
\end{tabular}

Sumber: data Primer (kuesuioner), diolah 2019

Berdasarkan output tabel di atas, menunjukkan bahwa nilai $\mathrm{F}_{\text {hitung }}$ sebesar 8,141 > $F_{\text {tabel }}=2,98$ dan taraf signifikan $0,001<0,05$. Hal ini berarti hipotesis yang menyatakan bahwa secara bersama-sama (simultan) variabel citra destinasi dan aksessibilitas wisata mempunyai pengaruh yang signifikan terhadap minat kunjung ulang.

Maka dalam hal ini $\mathrm{H} 4$ diterima dan $\mathrm{H} 0$ ditolak. Dengan demikian dapat disimpulkan bahwa citra destinasi, aksessibilitas dan motivasi wisata secara bersama-sama 
berpengaruh terhadap minat kunjung ulang wisatawan wisata bahari Desa Benan.

\section{Uji Koefisien determinasi $\left(\mathbf{R}^{\mathbf{2}}\right)$}

Berdasarkan tabel 7, maka dapat di lihat Adjusted $R$ Square dalam penelitian ini adalah sebesar 0,425 hal ini menunjukkan bahwa sebesar $42,5 \%$ persentase sumbangan pengaruh variabel independen yaitu citra destinasi dan aksessibilitas wisata terhadap minat kunjung ulang.

Sedangkan sisanya sebesar $57,5 \%$ dipengaruhi oleh variabel lain yang tidak dimasukkan dalam model penelitianini.

\section{Tabel 7}

\section{Uji Koefisien determinasi $\left(\mathbf{R}^{\mathbf{2}}\right)$}

\begin{tabular}{|l|l|l|r|r|}
\hline Model & $\mathrm{R}$ & $\begin{array}{l}\mathrm{R} \\
\text { Square }\end{array}$ & $\begin{array}{l}\text { Adjusted } \\
\text { R Square }\end{array}$ & $\begin{array}{l}\text { Std. Error of } \\
\text { the Estimate }\end{array}$ \\
\hline 1 &, $696^{\mathrm{a}}$ &, 484 &, 425 &, 859 \\
\hline
\end{tabular}

Sumber: data Primer (kuesuioner), diolah 2019

\section{Pembahasan}

\section{Pengaruh Citra Destinasi Terhadap Minat} Kunjung Ulang

Berdasarkan hasil pengujian yang telah dilakukan, diperoleh nilai thitung untuk variabel citra destinasi 2,765 dengan hasil sig. $0,010<0,05$ dan berdasarkan perbandingan thitung dengan ttabel (ttabel $\alpha=0,05, \mathrm{df}=27$ ) didapat thitung 2,765 lebih besar dari ttabel 1,70329 (2,765 $>1,70329)$ maka H0 ditolak dan H1 diterima, dapat disimpulkan bahwa citra destinasi (X1) berpengaruh signifikan terhadap minat kunjung ulang (Y).

Hal ini menunjukkan bahwa semakin tinggi dan bagus citra destinasi wisata bahari Desa Benan maka akan semakin tinggi pula minat kunjung ulang wisatawan wisata bahari Desa Benan. Semakin bagus suatu tempat atau citra destinasinya maka akan memacu niat orang-orang untuk mengulangi kunjunganya dikemudian hari.

Hasil penelitian ini sejalan dengan hasil penelitian yang dilakukan oleh Hidayat dan
Sutomo (2017) dalam penelitian yang berjudul 'Pengaruh Aksesbilitas Dan Citra Destinasi terhadap Niat Berkunjung kembali Ke Telaga Tambing" citra destinasi secara parsial berpengaruh signifikan terhadap niat berkunjung kembali.

\section{Pengaruh Aksessibilitas Terhadap Minat Kunjung Ulang}

Berdasarkan hasil pengujian yang telah dilakukan, diperoleh nilai thitung untuk variabel aksessibilitas 3,044 dengan hasil sig. 0,005 $<0,05$ dan berdasarkan perbandingan thitung dengan ttabel (ttabel $\alpha=0,05, \mathrm{df}=27$ ) didapat thitung 3,044 lebih besar dari ttabel 1,70329 (3,044 >1,70329) maka H0 ditolak dan H1 diterima, dapat disimpulkan bahwa Aksessibilitas (X2) berpengaruh signifikan terhadap minat kunjung ulang (Y).

Hal ini menunjukkan bahwa semakin bagus dan tersedianya aksessibilitas wisata bahari Desa Benan maka akan semakin tinggi pula minat kunjung ulang wisatawan wisata bahari Desa Benan. Semakin mudah suatu tempat untuk di akses maka niat untuk mengujungi kembali suatu tempat tersebutpun akan semakintinggi.

Hasil penelitian ini sejalan dengan hasil penelitian yang dilakukan oleh Hidayat dan Sutomo (2017) dalam penelitian yang berjudul 'Pengaruh Aksesbilitas Dan Citra Destinasi terhadap Niat Berkunjung kembali Ke Telaga Tambing" penelitian ini menunjukan bahwa variabel aksesibilitas berpengaruh positif dan signifikan terhadap niat berkunjung kembali.

\section{Pengaruh Citra Destinasi dan Aksessibilitas Wisata Terhadap Minat Kunjung Ulang}

Berdasarkan pengujian yang dilakukan menunjukkan bahwa nilai $\mathrm{F}_{\text {hitung }}$ sebesar 8,141 > $F_{\text {tabel }}=2,31$ dan taraf signifikan $0,001<0,05$. Hal ini berarti hipotesis yang menyatakan bahwa secara bersama-sama (simultan) variabel citra destinasi dan aksessibilitas wisata mempunyai pengaruh yang signifikanterhadap minat kunjung ulang. Maka dalam hal ini H3 
diterima dan H0 ditolak. Dengan demikian dapat disimpulkan bahwa citra destinasi dan aksessibilitas wisata secara bersama-sama berpengaruh signifikan terhadap minat kujung ulang wisatawan wisata bahari Desa Benan.

Berdasarkan hasil analisis data dan pembahasan yang telah dilakukan oleh peneliti, dapat disimpulkan bahwa diantara variabel bebas yaitu citra destinasi (X1), aksessibilitas wisata (X2) yang mempunyai pengaruh paling dominan terhadap minat kunjung ulang wisatawan wisata bahari Desa Benan yaitu aksessibilitas (X2) dengan nilai thitung sebesar 3,044 dan probabilitasnya sebesar sig: 0,005.

Aksessibilitas menjadi variabel yang paling dominan memengaruhi minat kunjung ulang karena aksessibiltas secara teknis berhubungan dengan citra destinasi, aksesibilitas merupakan sarana dan prasarana yang paling utama untuk seorang wisatawan dapat mengunjungi suatu tempat wisata. Dengan adanya aksessibilitas maka akan mempermudah wisatawan untuk melakukan kujungan wisata untuk menikmati destinasi wisata dan akan mendorong minat kunjung ulang wisatawan terhadap suatu tempat.

\section{IV.KESIMPULAN}

\section{Kesimpulan}

Berdasarkan hasil analisis dan pembahasan pada bab sebelumnya, maka kesimpulan yang dapat diambil dari penelitian ini adalah sebagai berikut:

1) Pengujian secara parsial membuktikan bahwa citra destinasi berpengaruh signifikan terhadap minat kunjung ulang wisatawan wisata bahari Desa Benan dengan nilai perbandingan $t_{\text {hitung }}$ dengan $t_{\text {tabel }}$ didapat $t_{\text {hitung }} 2,765$ lebih besar dari $t_{\text {tabel }}$ $1,70329(2,765>1,70329)$.

2) Pengujian secara parsial membuktikan bahwa aksessibilitas secara parsial berpengaruh signifikan terhadap minat kunjung ulang wisatawan wisata bahari Desa Benan dengan nilai perbandingan $t_{\text {hitung }}$ dengan $t_{\text {tabel }}$ didapat $t_{\text {hitung }} 3,044$ lebih besar dari $t_{\text {tabel }} 1,70329(3,044>1,70329)$.

3) Pengujian secara simultan membuktikan bahwa citra destinasi dan aksessibilitas, wisata berpengaruh signifikan terhadap minat kunjung ulang wisatawan wisata bahari Desa Benan. dengan nilai perbandingan $F_{\text {hitung }}$ dengan $F_{\text {tabel }}$ didapat $F_{\text {hitung }} 8,141$ lebih besar dari $F_{\text {tabel }} 2,31$ $(8,141>2,31)$.

\section{DAFTAR PUSTAKA}

Aviolitasona, Gheraldin Bella. 2017. Pengaruh Citra Destinasi Terhadap Minat Kunjung Ulang Wisatwan Umbul Sewu Pengging, Boyolali. Skripsi.

Deksono, Favian Rachmadi. 2017. Pengaruh Motivasi Wisata Dan E-Wom Terhadap Minat Berkunjung Ke Daya Tarik Wisata Goa Pindul. Skripsi.

Ghozali, I. 2016. Aplikasi Analisis Multivariete Dengan Program Ib Spss 23 (8th Ed.). Semarang: Badan Penerbit Universitas Diponogoro.

Hayati, Fitri, Dkk. 2016. Pengaruh Citra Pariwisata Terhadap Minat Berkunjung Kembali : Studi Kasus Di Kabupaten Padang Pariaman. ISSN, 2541-3400. 27 Oktober 2016.

Hidayat, Taufik Tri Nur dan Sutomo, Maskuri. 2017. Pengaruh Aksesibilitas Dan Citra Destinasi Terhadap Niat Berkunjung Kemabali Ke Telaga Tambing, ISSN, 2443-3578. Vol. 3, No. 2, Mei 2017.

Sayanggbatti, Dilla Prayuda Dan Baiquni, M. 2013. Motivasi Dan Persepsi Wisatwan Tentang Daya Tarik Destinasi Terhadap Minat Kunjungan Kembali Di Kota Wisata Batu. ISSN 1411-9862. Vol.5, No. 2, Agustus 2013. 
Sugiyono. 2016. Metode Penelitian Kuantitatif, Kualitatif Dan $R \& D$. Bandung: Alfabeta.

Sugiyono. 2017. Metode Penelitian Kuantitatif, Kualitatif Dan $R \& D$. Bandung: Alfabeta.

Sujarweni, V.Wiratna, 2015.Meteodelogi penelitian bisnis danekonomi. Jogjakarta: PT. Pustaka baru.

Yuristasari, Nadia Anggraini. Dkk. 2016. Analisis Faktor Aksesibilitas Terhadap Perbedaan Tanah Di Kawasan Pusat Kota Di Kecamatan Gemolong Dan Kecamatan Sragen Kabupaten Sragen. ISSN 2337-845X. Vol. 5. No. 1. Tahun 2016. 